\title{
Cine documental y movimientos sociales en la era de Internet: discursos de control y prácticas de resistencia durante el G8 de Génova
}

\section{Serena Delle Donne Napoli}

\author{
Recibido: 05.04.2020 — Aceptado: 25.04.2020
}

\section{Titre / Title/ Titolo}

Le cinéma documentaire et les mouvements sociaux à l'ère d'Internet: discours de contrôle et pratiques de résistance pendant le G8 à Gênes

Discourses and Resistance Practices During the G8 in Genoa

Il cinema documentario e i movimenti sociali nell'era di Internet: discorsi di controllo e pratiche di resistenza durante il G8 di Genova

\section{Resumen / Résumé / Abstract / Riassunto}

El presente artículo se centra en analizar las relaciones de poder y resistencia que articulan nuestra contemporaneidad en situaciones de excepcionalidad política. Más concretamente, nuestro interés se dirige hacia el estudio de la relación entre globalización, Internet y producción de discursos a través de los audiovisuales en un contexto histórico, social y político determinado, esto es, la contra cumbre del G8 de Genova del año 2001.

Cet article se concentre sur l'analyse des relations de pouvoir et de résistance qui articulent notre contemporanéité dans des situations d'exception politique. Plus spécifiquement, notre intérêt est orienté vers l'étude des relations entre la mondialisation, l'Internet et la production de discours par l'audiovisuel dans un contexte historique, social et politique spécifique, à savoir le contre-sommet du G8 à Gênes en 2001.

This article focuses on analyzing the relationships of power and resistance that articulate our contemporaneity in situations of political exceptionality. More specifically, it addresses the study of the relationship between globalization, the Internet and the production of discourses through audiovisual works in a specific historical, social and political context, i.e. the counter-summit of the G8 in Genoa in 2001.

Questo articolo si concentra sull'analisi dei rapporti di potere e di resistenza che articolano la nostra contemporaneità in situazioni di eccezionalità politica. In particolare, il nostro interesse è rivolto allo studio del rapporto tra globalizzazione, Internet e produzione di discorsi attraverso l'audiovisivo in uno specifico contesto storico, sociale e politico, ovvero il contro-vertice del G8 di Genova del 2001.

\section{Palabras clave / Mots-clé / Key words IParole chiave}

Biopolítica, internet, documentales, movimientos sociales, G8.

Biopolitique, internet, documentaires, mouvements sociaux, G8.

Biopolitics, documentaries, social movements, G8.

Biopolitica, internet, documentari, movimenti sociali, G8. 
El presente artículo se centra en analizar las relaciones de poder y resistencia que articulan nuestra contemporaneidad en situaciones de excepcionalidad política. Por ello, consideramos fundamental partir por el estudio del fenómeno de la globalización entendido como elemento estructural del sistema socio-político actual. La precarización del trabajo y de la vida, la crisis ambiental, el calentamiento global, la violencia de género, los conflictos bélicos, los procesos migratorios, la pandemia de la COVID-19 -por nombrar solo algunos- son fenómenos globales que afectan de manera diferente a cada uno de los contextos territoriales. En ese sentido, la sociedad del presente implica una nueva configuración en la que lo transnacional establece distintas estructuras de poder entre los diferentes agentes políticos como estados, sociedad civil y movimientos sociales y genera nuevos conflictos a escala global.

La cuestión es desde dónde entender el fenómeno de la globalización y cómo caracterizarlo. En el presente artículo consideramos la globalización tanto un fenómeno capitalista como un fenómeno de base. La globalización capitalista se propone como un modelo social, económico y político, responsable de haber institucionalizado el poder del mercado y haberlo puesto por encima de las necesidades y libertades sociales y de las propiedades del medio-ambiente. Desde este punto de vista, la globalización capitalista ha acentuado la asimetría de poder entre las empresas y los Estados, produciendo una transferencia de poder desde los gobiernos hacia las corporaciones empresariales. Desde nuestro punto de vista, lo que estructura la política global contemporánea capitalista, no es tanto la extensión geográfica de las relaciones de mercado, sino el alcance del mercado hacia el control de un conjunto de relaciones, de bienes, servicios y actividades de la vida humana. Consideramos que el capitalismo no es solo una forma de organización de los modos de producción, sino también un modo de subjetivación.

La preocupación por la relación que hay entre producción de subjetividades y capitalismo no es reciente, ya a mitad del siglo XIX, Marx (1848) analizó el proceso de automatización de la clase obrera a la hora de rela- cionarse con la cadena de montaje. Evidentemente, con el fenómeno de la globalización capitalista, el desarrollo tecnológico y la crisis de los Estados, la intuición de Marx ha vivido y sigue viviendo varias reinterpretaciones. El análisis de la producción de subjetividades en el contexto capitalista global se extiende a otras categorías que tienen en cuenta elementos como género, raza, fenómenos migratorios y clase.

El mapa político-cognitivo que se nos presenta en la globalización capitalista es el de una sociedad en la que los seres humanos deben reconfigurar su idea de familia, trabajo, tiempo libre, consumo, espacio público y espacio privado. La precarización no es solo un concepto más propiamente relacionado con lo económico, sino que invade también el ámbito de las relaciones interpersonales, sexo-afectivas y familiares. Nos define una época de crisis de identidades, de re-negociación de significados: las comunidades, los géneros, las identidades y las subjetividades son conceptos que necesitan definirse bajo otros significados vivenciales y políticos.

En este sentido y a diferencia del modelo impuesto por la globalización capitalista, el fenómeno de la globalización desde abajo propone una reconfiguración socio-política basada en una de-estructuración de las categorías de opresión. Actores principales de esta lectura política sobre la globalización son los movimientos sociales; reales motores de las redes de organización a escala territorial, inter y transnacional. Se reivindican conceptos como la solidaridad, los derechos humanos, las libertades de autodeterminación de los pueblos y de las personas, la autorganización social, el desarrollo del medio-ambiente, el feminismo, el antimilitarismo, etc. A partir de estos temas específicos, los movimientos sociales promueven otro tipo de relaciones transnacionales y otro tipo de globalización no competitiva donde los elementos a desarrollar y globalizar son los bienes comunes.

Es importante observar los procesos sociopolíticos contemporáneos y más concretamente las relaciones de poder y resistencia entre los varios agentes políticos, centrándose con mayor atención tanto en la lectura de la globalización como proceso capitalista como en la de 
la globalización como fenómeno que se desarrolla desde la base. Solo problematizando la relación entre estos dos distintos y opuestos fenómenos ha sido posible evidenciar la complejidad de los efectos producidos por la globalización capitalista y visibilizar las posibilidades y los efectos de la globalización desde abajo a la hora de identificarlo como fenómeno capaz de influir en los equilibrios políticos a escala transnacional.

El fenómeno de la globalización ha cambiado irrevocablemente no solo las relaciones sociales entre sujetos y las relaciones económicas entre Estados, sino también las relaciones de poder entre los diferentes agentes soberanos. Este cambio en el sistema social y político ha generado un cambio también en relación con la gestión del orden público. Tal como evidencia Bauman (1999), la seguridad ciudadana se convierte en un elemento necesario de gestión del orden público; es por eso que en situaciones de excepcionalidad política se llega a considerar el uso de la violencia como herramienta útil llevada a cabo por el Estado a fin de gestionar situaciones consideradas conflictivas. De hecho, nuestro interés está dirigido hacia cómo se construyen los discursos y las realidades en situaciones especiales de excepción socio-política y hacia cómo actúan los agentes soberanos en dichas situaciones.

Por ello, es necesario tener en cuenta los motivos y las formas en las que la violencia del Estado se manifiesta entre nosotras y el por qué esa violencia se acepta, esto es, es necesario investigar sobre el uso de la violencia estatal como dispositivo represivo y como forma de funcionamiento de los Estados contemporáneos sin que estos padezcan de una declarada legitimidad. Agamben, en su libro Estado de Excepción (2010), explica desde dónde y por qué nace, se desarrolla y legitima la violencia de los Estados democráticos occidentales. El estado de excepción, según Agamben, se constituye como un punto de desequilibrio entre el derecho público y el hecho político. Es una tierra de nadie entre orden jurídico, derecho y vida. Este espacio permite la instauración de una guerra civil legal y continua en la que cualquier persona o grupo de personas que puede resultar amenazante para el sistema político puede ser eliminada físicamente. Es en esa situación, totalmente contemporánea, en la que el estado de excepción se constituye como elemento integrante de nuestros gobiernos occidentales. La excepción, de hecho, se hace regla. Hay que entender este estado de excepción no como un derecho especial, sino como el que define su límite, como una técnica de gobierno en toda regla. La preocupación de Agamben se centra justo en la instauración del estado de excepción como una técnica de gobierno permanente que amenaza con transformar radicalmente la estructura y las maneras en las que se entienden las constituciones.

Yendo más allá, desde nuestro punto de vista el problema está en estrecha relación con el estado de excepción, pero no se trata solo de un problema relacionado con el Estado, con el ámbito del derecho o con la Constitución, sino que es un problema más propiamente biopolítico. Es la manera en que estas nuevas formas de generar y mantener el poder se relacionan con la vida, con los sujetos y con las sociedades. Es el lugar en el que las leyes empiezan a no tener mucha relevancia política y en las que el poder del Estado y de las fuerzas militares está por encima, no solo de la jurisprudencia, sino también, y sobre todo, de las poblaciones, de las comunidades oprimidas y de cualquier forma de resistencia.

El estado de excepción, en realidad, se justifica y se relaciona con el concepto de necesidad. Su legitimidad se explica a través del status necessitatis, redactado en el Decretum de Graziano: la necesidad aquí actúa como justificación de una transgresión puntual e inmediata. El problema es que es evidente que en nuestra historia contemporánea, el estado de excepción, esta contemporánea forma de entender y aplicar el status necessitatis entendido como dispositivo momentáneo de gobierno, se ha convertido en una institución duradera también en tiempos de paz. Las luchas contra el terrorismo y por la seguridad ciudadana occidental pueden ser una demostración evidente de todo eso.

Relacionándose con el concepto de status necessitatis y al concepto de biopolítica de Foucault, Mbembe a través de las teorizaciones expuestas en Necropolitica 
(2011), considera que la expresión de soberanía reside básicamente en «el poder y la capacidad de decidir quién puede vivir y quién debe morir. Hacer vivir o dejar morir constituye, por tanto, los límites de la soberanía» (Mbembe, 20). El autor llega a definir la soberanía como el derecho de matar. Para usar su soberanía, el poder — que para Mbembe no se localiza solo en el papel del Estado - no hace otra cosa que entremezclar el concepto de estado de excepción, de urgencia, con «una idea ficcionalizada del enemigo» (Mbembe, 22). Trabaja también para construir y producir este tipo de realidad de emergencia. Esta situación de emergencia permanente es un constructo socio-político a través del cual la soberanía y el derecho a dejar vivir o deber morir se justifica constantemente, ganando legitimidad ciudadana y una necesidad persistente de seguridad.

Tal como afirma Castells:

El poder se ejerce mediante la coacción (o la posibilidad de ejercerla) y/o mediante la construcción de significado partiendo de los discursos a través de los cuales los actores sociales guían sus acciones. Las relaciones de poder están enmarcadas por la dominación, que es el poder que reside en las instituciones de la sociedad. La capacidad relacional del poder está condicionada, pero no determinada, por la capacidad estructural de dominación. (Castells, 13)

Entender el poder en términos biopolíticos y en términos de dominación nos permite investigar sobre las herramientas empleadas por los estados-nación a la hora de mantener su estabilidad y legitimidad política en un contexto socio-político global en el que los Estados han perdido su carácter hegemónico a la hora de mantenerse como agentes soberanos. Desde que el mundo se ha «globalizado», han cambiado las formas de entender los conceptos básicos de la sociedad moderna y han cambiado las dimensiones en las que el poder opera.

Hay que subrayar el hecho de que hoy en día, la vida y el cuerpo ya no son regulados unicamente a través de su paso por las instituciones disciplinarias sino a través de un conjunto de tecnologías digitales y de transmisión de información. Los cambios producidos tanto por los nuevos equilibrios transnacionales entre diferentes agentes políticos como por el desarrollo tecnológico hacen que vivamos en la que Castells define como sociedad red (44). Desde el punto de vista del autor la sociedad red surge ante el nuevo paradigma social de la revolución tecnológica basada en la información. Esta nueva conformación socio-política está formada por configuraciones concretas de redes globales, nacionales y locales en un espacio multidimensional de interacción social. La sociedad red global es una sociedad dinámica, fluctuante, en la que los equilibrios de poder, Estados y fuerzas locales, políticas y estrategias económicas se modifican y se pueden modificar constantemente. En la sociedad red la realidad se estructura a través de redes de información sin restricciones de tiempo, de espacio o de volumen. Evidentemente, este cambio es posible gracias al fenómeno de la globalización.

Examinar la contemporaneidad desde el concepto de sociedad red nos permite enmarcar el estudio de las relaciones de poder y resistencia como producto de la interconexión entre varios «nodos». Los nodos pueden tener mayor o menor relevancia para el conjunto de la red, de modo que los más importantes se denominan «centros». Las redes se reconfiguran constantemente según la necesariedad de cada nodo, habrá algunos innecesarios y otros fundamentales. En la vida social las redes son estructuras comunicativas. Según Castells:

Una sociedad red es aquella cuya estructura social está compuesta de redes activadas por tecnologías digitales de la comunicación [...]. Las redes digitales son globales por su capacidad para autorreconfigurarse de acuerdo con las instrucciones de los programadores, trascendiendo los límites territoriales e institucionales a través de redes de ordenadores comunicadas entre sí. Por tanto, una estructura social cuya infraestructura se base en redes digitales tiene las posibilidades de ser global. [...] La sociedad red es pues global (Castells, 85).

De facto, el desarrollo tecnológico e Internet han permitido la realización de nuevas formas de socialización; han cambiado nuestra manera de acceder y divulgar información, sentidos y saberes. Por Internet se puede comunicar, se pueden compartir textos, sonidos, ví- 
deos y cualquier otro artefacto que se pueda digitalizar. Nuestro estudio carecería de rigor científico si no se centrase en analizar la relación entre las estructuras de poder y estas tecnologías.

Nos comunicamos de forma inmediata, vivimos en una época en la cual cualquiera que tenga un móvil, una cámara o un aparato digital puede registrar contenidos capaces de difundirse rápidamente a través de la web. Eso, evidentemente, cambia nuestra cotidianidad, otorgando a la inmediatez un papel fundamental a la hora de difundir informaciones, saberes, sentidos, contenidos e historias personales y colectivas. Por esta razón, consideramos que llevar a cabo una reflexión sobre este medio y sobre sus contenidos nos permite observar sus potencialidades a la hora de participar en la construcción de nuevos discursos y de nuevas realidades.

Desde nuestro punto de vista, la relación entre el fenómeno de la globalización y el fenómeno de Internet ha generado un fuerte cambio en la relación entre medios de comunicación y producción de sentidos y discursos, reestructurando la entera cadena de relaciones entre sujetos y los diferentes agentes políticos. Problematizar este aspecto significa observar con mejor exactitud las realidades que nos rodean y los sistemas de construcción de discursos en el contexto occidental capitalista. Más concretamente, nuestro interés, que nunca deja de lado la propuesta impulsada por los movimientos sociales de la globalización desde abajo, está dirigido a examinar Internet desde su potencialidad transformadora.

En Occidente, la difusión y el consumo de contenidos audiovisuales por Internet está al alcance de cada vez más personas y modifica nuestra experiencia como realizadoras y espectadoras de tales contenidos. Más concretamente, el carácter más o menos abierto de Internet ha permitido la realización y difusión de contenidos audiovisuales amateur y militantes. Entendido desde esta perspectiva, se hace fundamental reflexionar sobre la necesidad política de aprovechar estos territorios para desarrollar nuevas formas de entender, representar e interpretar las distintas realidades que nos rodean. Por esta razón, consideramos observar en qué medida la relación entre sociedad red, globalización desde abajo y desarrollo tecnológico ha permitido la realización y difusión de películas militantes en Internet; hecho que, además, nos obliga a reflexionar sobre el uso de los contenidos audiovisuales como herramientas de intervención política y transformación social.

El presente artículo presta especial atención a las implicaciones políticas de Internet considerándolo como un medio capaz de influir en los equilibrios políticos a escala transnacional y generar nuevos y diferentes discursos y realidades.

Más concretamente, nuestro interés se dirige hacia el estudio de la relación entre globalización, Internet y producción de discursos a través de los textos audiovisuales en un contexto histórico, social y político determinado, esto es, la contra-cumbre del G8 de Genova del año 2001. Desde nuestro punto de vista, los acontecimientos del G8 de Génova nos ofrecen elementos de especial interés para abordar la relación entre políticas de resistencia y políticas represivas a principio del siglo XXI. Este momento histórico puede ser representativo a la hora de observar cómo se articulan y representan las relaciones de poder en el mundo globalizado de Occidente.

Hay que remarcar que la protesta de la contra-cumbre del G8 de Génova tiene unos antecedentes históricos concretos. Desde 1994 el movimiento en contra de la globalización capitalista que se manifestó en Génova generó agendas comunes, encuentros, debates, manifestaciones y protestas en todo el mundo: en 1994 en Chiapas con el surgimiento del movimiento zapatista y en Madrid con motivo del 50 aniversario del Fondo Monetario Internacional; en 1999 en Seattle, Bangkok y Washington; en 2000 en Praga, con la finalidad de impedir la reunión conjunta del Fondo Monetario Internacional y el Banco Mundial. En este contexto, las políticas represivas fueron bastante violentas: tanto en 1999 en Seattle como en Praga, Nápoles, Génova, Gotemburgo, Barcelona y Salzburgo. Más de diez años de luchas locales y globales nos demuestran que tanto el proyecto desde la base como las políticas represivas de los Estados se desarrollaron de forma global. 
En este momento histórico particular, en un contexto político de represión policial y militar, tuvo lugar el summit de G8 de Génova de 2001. Durante los días 19, 20, 21 y 22 de julio de 2001 se desarrolló en Génova el G8; se reunieron los representantes de los ocho países más industrializados del mundo cuyo peso político, económico y militar es muy relevante a escala global. Desde Seattle, la crítica a las cumbres del G8 o de la OMC, del Banco Mundial o de la OTAN, se fue haciendo más fuerte políticamente y más violenta en las manifestaciones. Es por ello que la decisión de realizar la cumbre del G8 en Génova suscitó polémica ya meses antes del encuentro, porque dicha ciudad no se consideraba adecuada para garantizar la gestión del orden público.

Varios días antes del encuentro entre los representantes de los países más industrializados del mundo, los medios de comunicación italianos (radio, televisión y prensa) difundieron una noticia según la cual el desarrollo de actos violentos durante las manifestaciones contra la cumbre del G8 era casi inevitable. Las autoridades aconsejaron a los y las habitantes de Génova alejarse de la ciudad, y a la gente que decidió quedarse se les pedía un documento de identidad que certificara la zona en la que vivía; si el documento no lo certificaba, los y las habitantes de Génova no podían circular libremente dentro de la ciudad. Mientras tanto, los medios de comunicación daban gran cobertura a las medidas de seguridad adoptadas, creando así un clima de tensión e incertidumbre muy alto en la población.

La ciudad fue dividida en tres zonas, según la modalidad de acceso: a) Zona Rossa (Zona Roja), se definió así al perímetro que rodeaba el lugar en el que se realizó la cumbre del G8, era una zona absolutamente reservada a la que solo podían acceder los residentes a través de un número limitado de check points; b) Zona Gialla (Zona Amarilla), una amplia zona en torno a la Zona Roja, cuyo acceso estaba limitado a los y las habitantes de Génova; c) por último, el resto de la ciudad (Zona Verde), a la que se podía acceder libremente. En realidad, el acceso a toda la ciudad se hizo muy complicado dado que se cerraron la estación de tren, el puerto y el aeropuerto, donde se colocaron baterías de misiles tierra-aire. Los comercios cerraron, los hoteles no daban alojamiento a quienes vinieran de fuera, las alcantarillas se sellaron, los contenedores se eliminaron y se prefiguraron escenarios apocalípticos de guerra química. Incluso llegó a plantearse la posible presencia de globos llenos de sangre infectada.

En este clima de tensión y militarización de la ciudad se hizo posible el alto nivel de violencia de la policía y de las fuerzas militares contra los y las manifestantes. La posibilidad de que las personas que participaron en la contra-cumbre creasen situaciones de peligro justificó posibles acciones de represión militar: el G8 de Génova acabó cuatro días después con doscientos personas presas, miles de personas heridas y un manifestante asesinado, Carlo Giuliani.

Desde nuestro punto de vista, lo que 'Génova' representa fue un antes y un después de la legitimización institucional y ciudadana sobre la gestión de la vida en una época política en la que el concepto de globalización iba a ser fundamental a la hora de entender la cotidianidad de todos los sujetos políticos. Es por eso que la contra-cumbre del G8 de Génova se manifiesta como un evento simbólico a la hora de leer las políticas represivas y resistentes. El caso de Génova no es importante solo para explicar y contextualizar las nuevas medidas antiterroristas desarrolladas poco después del ataque a las Torres Gemelas de Nueva York, sino también para ver cómo en Europa empieza a desarrollarse la llamada «tolerancia cero» por parte de las fuerzas del orden y de las instituciones estatales durante eventos entendidos como peligrosos para el desarrollo de las políticas económicas mundiales.

Se podría entender o pensar en el G8 de Génova como hecho excepcional. Desde nuestro punto de vista, habría que afirmar, más bien, que hace referencia a una manera de desarrollar el poder a través de una adaptación del control social. Consideramos que prácticas de control y estrategias de miedo fueron los dispositivos básicos a través de los cuales actuó el Estado italiano durante la contra-cumbre del G8 para, por un lado, generar la legitimidad ciudadana necesaria para utilizar la herramienta de la violencia policial y militar, y por otro, 
para paralizar y castigar todo un movimiento social a escala global. En esta circunstancia, vemos los excesos de la soberanía, hasta dónde puede llegar su poder y su legitimidad.

Los movimientos sociales contestaron de múltiples formas a las políticas represivas desarrolladas durante la contra-cumbre del G8 de Génova: manifestaciones, piquetes, concentraciones, charlas, denuncias legales, proyecciones en espacios sociales, realización de documentales, difusión de películas militantes por Internet, entrevistas en varios medios de comunicación, etc.

Con respeto a las diferentes formas y prácticas de resistencia desarrolladas en relación con la contra-cumbre del G8 en Génova, consideramos de suma importancia estudiar los alcances y las características de los textos audiovisuales realizados en relación con los acontecimientos del G8 de Génova ya que vemos en esos la posibilidad de generar nuevos discursos, nuevas memorias colectivas y, por ende, la posibilidad de participar en la configuración de la estructuración de las relaciones de poder y resistencia en el contexto contemporáneo occidental.

En relación con el G8 de Génova, hasta hoy en día se han realizado veintiséis películas militantes, todas fácilmente accesibles a través de Internet. Los filmes corresponden a la necesidad de compartir informaciones diferentes de las desarrolladas por los medios de comunicación de masas institucionales, generar nuevos sentidos y discursos respecto a las políticas del movimiento social y difundir otra memoria colectiva visibilizando y denunciando las políticas violentas llevadas a cabo por el Estado italiano. Las películas representan, por un lado, las violencias desarrolladas por las fuerzas del orden hacia las personas manifestantes durante la contra-cumbre del G8 de Génova, y por el otro, los cuatro días de manifestación y de reivindicación política.

Es importante subrayar que desde nuestro punto de vista, lo que se representa en un texto documental no es una reproducción fidedigna de la realidad, sino que es una construcción discursiva de un sentido que se postula fidedigno a un determinado aspecto de la realidad (Zumalde y Zunzunegui, 2014). Consideramos fundamental negar al texto documental su carácter de representación fidedigna de la realidad, esto nos ofrece la posibilidad de analizarlo e interpretarlo teniendo en cuenta lo que más nos parece relevante, esto es, cómo se construyen y ficcionalizan los discursos.

De los veintiséis filmes realizados hasta la actualidad sobre los acontecimientos del G8 de Génova, hemos elegido analizar dos películas teniendo en cuenta: (1) la distribución a través de plataformas mediática; (2) el elevado número de usuarios/as y espectadores/as que han tenido acceso a las películas y que han podido visionarlas y (3) la relevancia y visibilización que estas han recibido en los ámbitos de los movimientos sociales (proyecciones en asociaciones, círculos, centros sociales, salas cinematográficas independientes, etc.). Las películas analizadas en el presente artículo son: Bella Ciao (Giusti y Torelli, 2001) y Black Block (Bachschmidt, 2011).

El documental Black Block, realizado en 2011 por Carlo Bachschmidt, producido por Fandango y retransmitido el mismo año por Rai Tre, el tercer canal televisivo estatal de Italia, se centra, a lo largo de sus setenta y seis minutos, en los acontecimientos avenidos durante la contra-cumbre del G8 de Génova.

En los días 19, 20, 21 y 22 de julio de 2001, cuatrocientas organizaciones italianas y trescientas internacionales, más la gente que fue a manifestarse de forma autónoma y a título individual, se reunieron para protestar contra el summit del G8. Quien organizó y coordinó los diferentes movimientos fue el llamado Genoa Social Forum. Las escuelas Diaz y Pertini y el estadio Carlini se convirtieron en los principales puntos de referencia para las personas activistas. El primer día de manifestaciones, cincuenta mil personas desfilaron al lado de la gente migrante. Mientras tanto, en el estadio Carlini, el bloque de las/los Disobbedienti se construyó sus escudos de plexiglás y abrigos de gomaespuma para asaltar simbólicamente la Zona Roja. La otra parte del movimiento decidió seguir desfilando por las calles de Génova. A la mañana siguiente entraría en acción el llamado Bloque Negro, que pasaría a la historia como Black Block. La estrategia política de este bloque consistió en atacar los 
símbolos más evidentes del capitalismo, como bancos, multinacionales, coches de lujo como BMW, etc.

El segundo día de manifestaciones, las cargas de las fuerzas del orden se hicieron más violentas. En la plaza Alimonda, un Land Rover Defender con tres carabinieri dentro quedó bloqueado por un contenedor de basura y aquí, el joven manifestante Carlo Giuliani fue disparado y asesinado por el carabiniere Marco Placanica. El día siguiente la gente volvió a manifestarse. Una vez más, el ataque policial fue violento, se utilizaron gases lacrimógenos tóxicos y urticantes. Al final del día el balance era ya de unos/as cientos de heridos/as y una docena de presos/as. Muchas de las quinientas personas presas en esos días denunciaron la violencia física y psicológica de la policía en la comisaría de Bolzaneto, constituida como cárcel especial para esta ocasión concreta. La misma noche, cuando ya el último día de manifestación había terminado, la policía asaltó la escuela Diaz, lugar en el que permanecía muchísima gente del extranjero, sobre todo europea. Noventa y tres personas, entre manifestantes y periodistas, fueron sorprendidas en mitad de la noche y agredidas. Decenas de personas salieron en camillas, sesenta fueron llevadas al hospital, tres con pronóstico reservado, las imágenes mostrarían paredes y suelos casi completamente cubiertos de sangre. Todas estas personas fueron encarceladas, algunas fueron soltadas aquella misma noche, otras, días después. En la escuela, la policía encontró algunas barras de metal, pertenecientes a las obras que se estaba llevando a cabo en el edificio, y dos cócteles molotov que, según se supo después gracias a las investigaciones judiciales, fueron llevados a la escuela por los mismos policías con el objetivo de crear pruebas falsas.

En la película Black Block se estructura el relato a través de las entrevistas a seis personas, cuatro hombres y dos mujeres, se enuncia la historia de quienes vivieron en primera persona la violencia de la incursión policial en la escuela Diaz y las torturas en la comisaria/cárcel de Bolzaneto y Voghera. En la narración coral de los y las entrevistadas, tiene gran protagonismo la historia del personaje principal, Muli, un chico alemán de 31 años en el momento en el que se realizó la entrevista que par- ticipó en las manifestaciones de la contra-cumbre del G8 y que sufrió las agresiones policiales en la escuela Diaz.

La entrevista se concibe como una herramienta útil a fin de generar una coherencia discursiva que define el efecto de realidad y verdad (Nichols, 1997). Podemos afirmar que la herramienta de la entrevista en Black Block confiere al filme este carácter de credibilidad y consigue instaurar un pacto de verdad con el público; la palabra hablada de las seis personas entrevistadas en la película constituye el instrumento útil para la identificación espectatorial y cumple con el placer escopofílico y de conocimiento por parte de la persona espectadora.

La película está rodada en tres lugares: en la ciudad de Berlín (ciudad donde empieza y acaba la entrevista al personaje principal, Muli), en la ciudad de Génova y en la escuela, escenografía en la que se desarrollan las entrevistas. Se representan estos tres lugares a través no solo de las imágenes grabadas por las personas que han realizado el documental, sino también a través de la recuperación de los vídeos amateur. La representación de la ciudad de Génova durante la manifestación se mezcla con la representación de la misma ciudad después del G8, mostrando así dos caras de la misma ciudad, mostrando la Génova normal, la que hace referencia a la cotidianidad, y la otra Génova, la que hace referencia al momento histórico concreto, a lo extraño y a lo diferente, al caos de los días del G8.

Este puede considerarse como un primer elemento que define las tecnologías biopolíticas puestas en acción durante la contra-cumbre del G8 de Génova: el documental muestra los comercios cerrados, las calles y confines vigilados y militarizados, las rejas que dividen la Zona Roja de la Zona Verde. El documental define la ciudad como lugar de conflicto, como zona de guerra. La isotopía entre el antes y el después de la Génova de la contra-cumbre, se desarrolla a través del montaje alternado que restituye al público no solo el conflicto, sino también aquella condición de estado de excepción permanente, de virtualización terrorífica de la ciudad a través de las violencias infligidas a las personas que se manifestaron en aquellos días. El lugar en el que se de- 
sarrolla la acción es un espacio militarizado en el que se manifiesta claramente quién está allí para ser protegido (los representantes de los ocho países más potentes) y quién está para ser vigilado/a, agredido/a y castigado/a.

Black Block empieza con la representación de un video amateur que nos presenta la otra Génova, la del G8, y con un plano de conjunto en picado de la multitud de gente que invade las calles de la ciudad, mientras se escucha la voz del jefe de la policía durante la cumbre del G8, Gianni De Gennaro, que explica las motivaciones del asalto a la escuela Diaz. En voice off, mientras las imágenes reproducen un rodaje aéreo tomado en directo de la manifestación, se escucha la grabación de la voz de Gennaro que dice que:

Ha sido posible identificar a un grupo de quinientos italianos y dos mil extranjeros. Ellos [las personas que formaban parte del Black Block] suelen moverse de forma anónima, no siempre tienen una sede, no se encuentran habitualmente, pero se reúnen en todas partes del mundo, sobre todo en ocasiones de eventos significativos, con un conocimiento perfecto del territorio y de las técnicas de agresión. ${ }^{1}$

El documental relata cómo la policía italiana encuentra, identifica, nombra y estudia al «enemigo». Un enemigo que se identifica con el extranjero (y aquí uso solo el masculino deliberadamente), y con el extraño: de hecho, la persona perteneciente al Black Block no solo es terrorista (o sea, extraña) sino también extranjera (tal como nos informa la película, dos mil personas del Bloque Negro se identificaron como extranjeras, mientras que solo quinientos con personas de nacionalidad italiana). Se establece una relación con las teorías propuestas por Mbembe (2011) a la hora de definir, en la necesidad de la construcción de la idea de un enemigo ficticio y ficcionalizado, una de las tecnologías empleadas por la necropolítica a la hora de generar políticas violentas. Dentro del análisis del documental, este enemigo, de

1 Traducción del italiano: «Essi sono soliti spostarsi in forma anonima, non sempre hanno una sede, non si incontrano abitualmente, ma si raccolgono da tutto il mondo soprattutto in occasione di eventi significativi con una conoscenza perfetta oltre che del territorio anche delle tecniche di aggressione». momento, se puede identificar con el sujeto participante del Bloque Negro.

En Black Block, el desarrollo de la función punitiva del poder se manifiesta a través del castigo sobre los cuerpos de las personas manifestantes. Ese control se manifiesta por medio de las tácticas y estrategias militares, los golpes físicos y psicológicos, la inmovilización, la aterrorización.

Consideramos que, desde nuestra perspectiva, las tecnologías biopolíticas se reproducen y representan a través de los siguientes aparatos técnico-discursivos: la visibilización de la segregación del espacio urbano y su división en Zona Verde, Amarilla y Roja; de la creación ficcionalizada del enemigo identificado en el/la black block; del miedo y del sentimiento de inseguridad de la ciudadanía; de la percepción de una situación de emergencia y de peligro por los y las habitantes de Génova; de la representación a través de los seis testimonios y de las imágenes amateur de la tensión, del miedo a morir, de los aparatos de guerra como gas lacrimógeno, camionetas, pistolas y uniformes de las fuerzas del orden, de los cuerpos ensangrentados (Fotograma 1), golpeados (Fotograma 2), heridos, violados, abusados y asesinados, la violencia de las fuerzas del orden (Fotograma 3), las intimidaciones físicas y psicológicas, la cárcel, las crisis de pánico, etc.

Todos estos elementos llegan a representar con claridad unas prácticas políticas muy afines a una situación

Fotograma 1

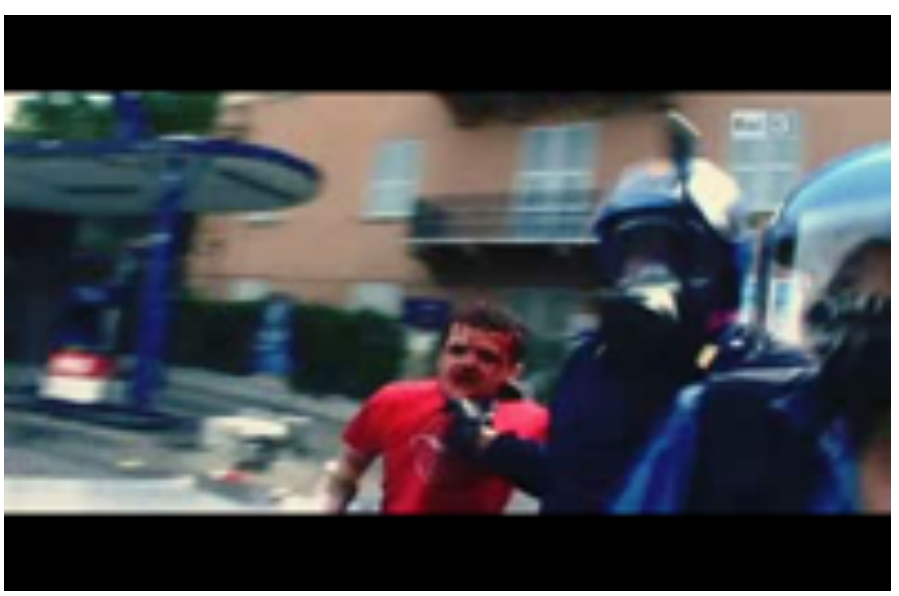



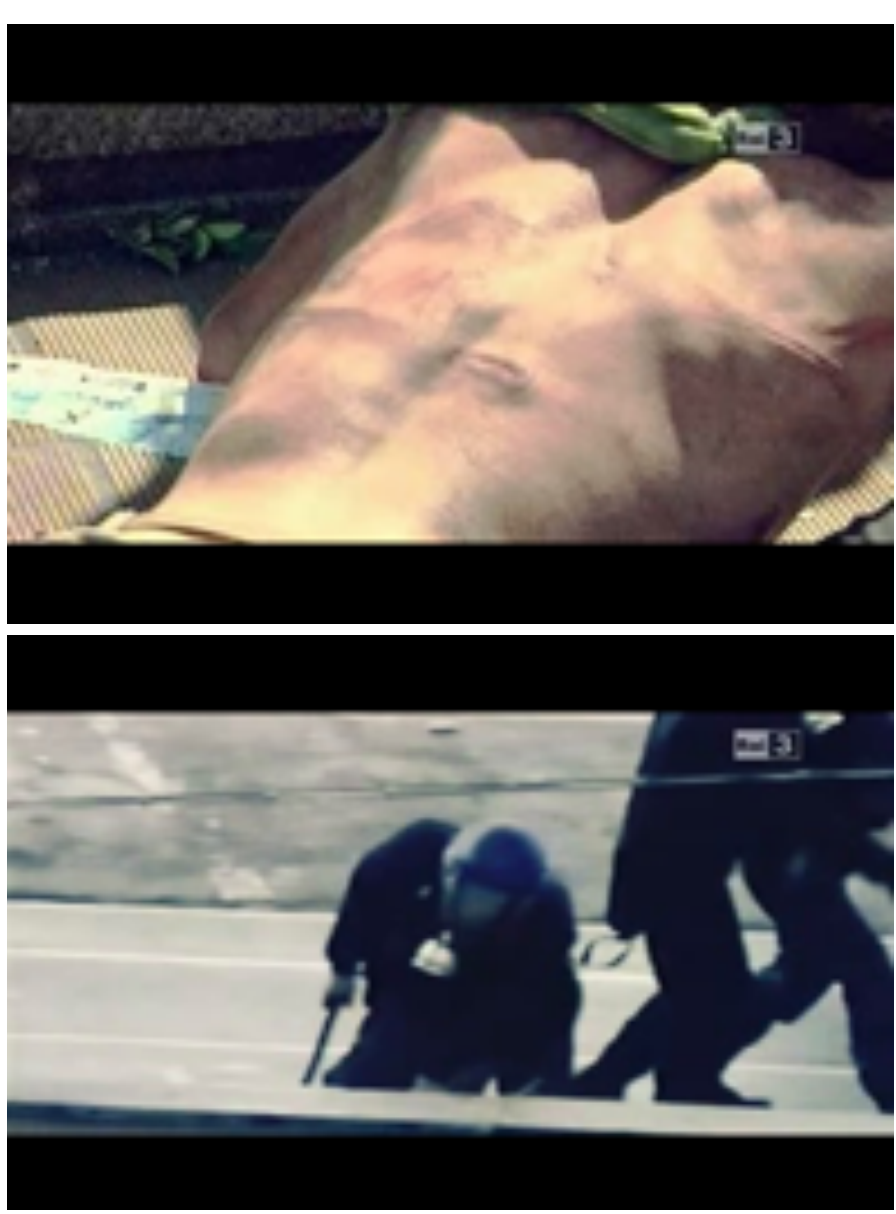

Fotograma 2 (arriba), fotograma 3 (abajo)

política de estado de excepción, mezclado con tecnologías del miedo. A través del análisis de este texto filmico, es posible afirmar que la violencia gubernamental realizada durante el G8 de Génova entra en el estado de excepción y de derecho como elemento fijo que decreta el poder de la soberanía sobre la vida y sobre la muerte de los sujetos: el poder sobre la vida avalaría así el poder de dar la muerte. La película Black Block representa nuevas formas de control y de dominación de los sujetos y de las comunidades que se pueden identificar con los aparatos necropolíticos a través de la instauración de un estado de excepción y de una idea ficcionalizada del enemigo. Durante el G8 de Génova, este estado de excepción y de emergencia llegó a identificarse con la injustificada sensación de amenaza causada por las manifestaciones desde abajo, y con la idea ficcionalizada y la identificación de los/las manifestantes como el enemigo, además de la segregación espacial en diferentes zonas.

La representación de las estructuras necropolíticas puestas en acto durante la contra-cumbre del G8 de Génova se hace visible también en el documental Bella Ciao. El filme de 2001 de Marco Giusti, Sal Mineo y Roberto Torelli, tiene una duración de 116 minutos y fue realizado, distribuido y difundido por medios de comunicación independientes como las plataformas Indymedia y Vimeo. Su relato se basa en la representación de las manifestaciones y en las violencias realizadas durante la contra-cumbre del G8 de Génova. Es importante recordar que durante el G8 de 2001 y en los meses siguientes, los medios de comunicación oficiales difundieron la información según la cual los ataques violentos de los cuerpos militares se produjeron debido al alto nivel de peligrosidad de la gente que participó en las manifestaciones, una peligrosidad que alcanzaba niveles de «terrorismo». El documental Bella Ciao reivindica y explica la posición de las personas que se manifestaron, para representarlas de un modo que los medios de comunicación habían ignorado con el objetivo de legitimar la actuación de las fuerzas policiales y de las órdenes del Gobierno de entonces.

En la película aparece la composición de imágenes, de palabras, de testimonios de un ataque brutal, del uso de los instrumentos de la violencia de Estado contra un grupo de manifestantes inermes, de la crueldad como instrumento de intimidación. La violencia ejercida sobre los cuerpos es uno de los elementos más presentes en la película.

El documental empieza con la representación del momento más violento de los días de la contra-cumbre: el asesinato de Carlo Giuliani. El vídeo amateur nos muestra que es el 21 de julio y que son las 5.27 de la tarde (Fotograma 4): un plano de conjunto nos muestra una furgoneta de los carabinieri y alrededor de ella unos manifestantes, en voice in escuchamos la vOz del mismo realizador del video que, moviendo la cámara a mano y generando un movimiento violento hacía abajo y un desenfoque repentino de la imagen, grita: $«_{j} \mathrm{Oh}$ 


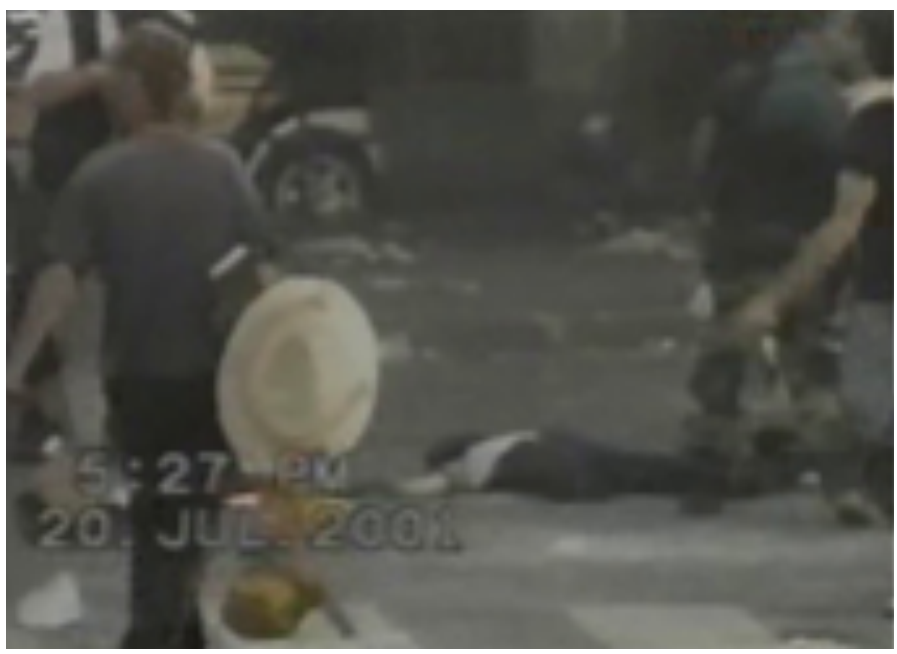

Fotograma 4

Dios mío, joder, hay uno en el suelo! ¡Oh Dios mío, no! ¡Mierda!». La imagen vuelve a enfocar la camioneta $\mathrm{y}$, con un movimiento hacía la derecha y el efecto zoom, encuadra un cuerpo inmóvil tirado en el suelo. El cuerpo de Carlo Giuliani aparece sin vida en la pantalla. Así lo denota la típica 'relajación' de los cuerpos recién muertos, no hay ninguna tensión muscular, el cuerpo se hace cadáver delante de nuestros ojos.

En el minuto 4, el documental nos muestra la representación de la incursión policial en escuela Diaz. Vemos a un policía de pie y a todas las personas sentadas en el suelo. En plano de conjunto, el cuerpo del policía se muestra en posición frontal y central, mientras que los cuerpos de las personas presentes en la Diaz se muestran sentados y en fila, distribuidos en los extremos derecho e izquierdo tanto de la habitación como del encuadre (Fotograma 5).

Fotograma 6

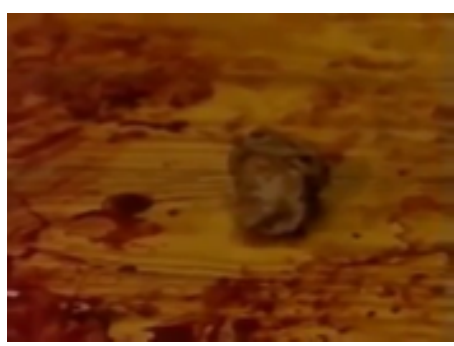

Fotograma 7

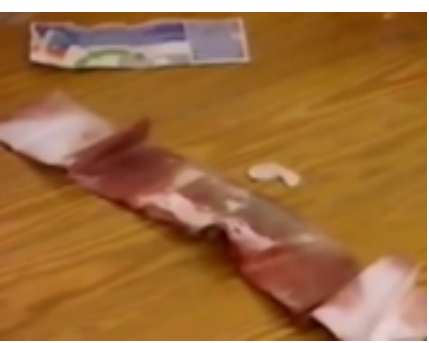

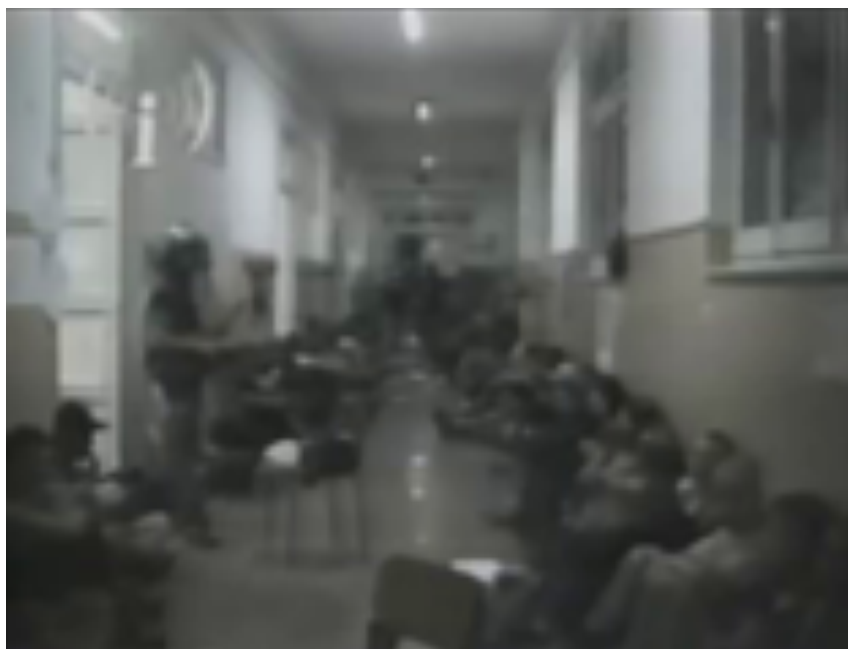

Fotograma 5

A los 5 segundos se muestra la irrupción de los policías que entran en la escuela. A través de las imágenes amateurs vemos la actuación policial sobre los cuerpos de la gente, los porrazos y los golpes, las personas arrastradas y cogidas por el pelo, mientras que la banda sonora que reproduce la canción Bella Ciao se hace más contundente a través de una subida de volumen. La música cesa repentinamente a fin de introducirnos en el contexto post-asalto a la escuela Diaz. Escuchamos el sonido de las ambulancias y vemos gente en camillas, varias ambulancias, cuerpos heridos, rostros ensangrentados. Las imágenes amateurs recogen los primeros testimonios, en uno de ellos reconocemos a un joven, Michael, una de las seis personas entrevistadas en la película Black Block. A la representación de los testimonios le siguen las imágenes de las manchas de sangre presentes en la escuela Diaz (Fotogramas de 6 a 9). El texto

Fotograma 8

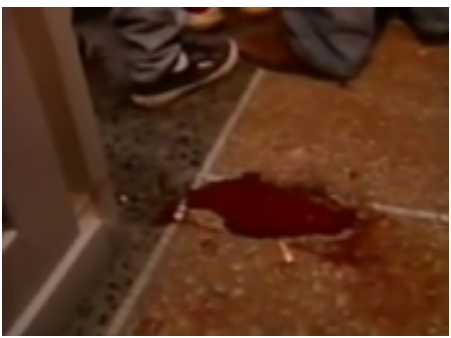

Fotograma 9

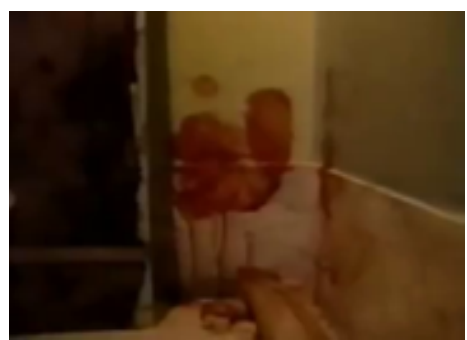




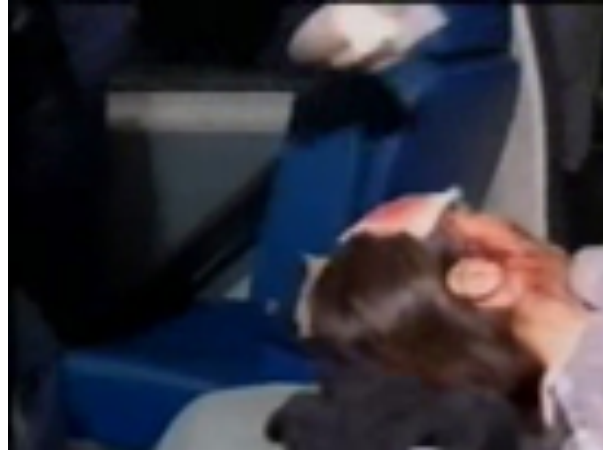

Fotograma 10

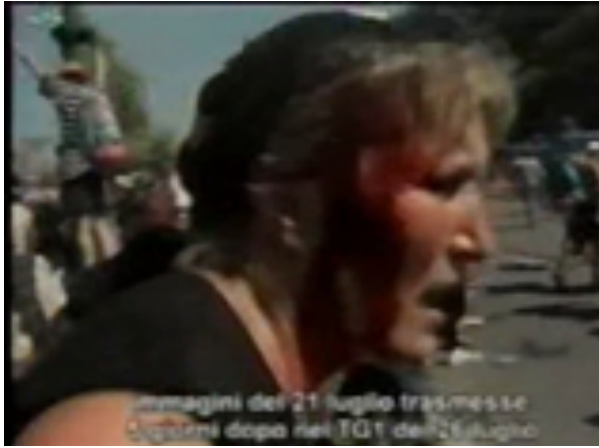

Fotograma 11

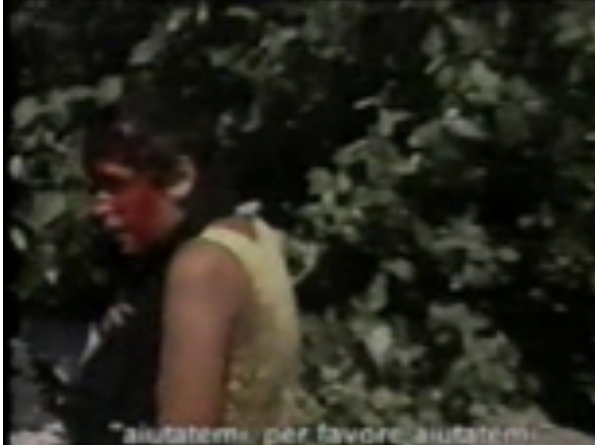

Fotograma 12 nos presenta las violencias de las fuerzas del orden, los cuerpos ensangrentados en las camillas, la sangre dispersa por toda la escuela Diaz, los gritos de las personas manifestantes.

Respeto a la representación de los cuerpos en la película, podemos evidenciar que la mayoría de cuerpos que socialmente se identifican con el género femenino que veremos en este documental aparecerán representados como cuerpos maltratados, agredidos físicamente, que se quejan, que gritan o que organizan técnicamente la manifestación misma. Sobre los cuerpos de mujeres agredidos y en posición de víctima hay varios ejemplos: cuando se representa el momento de la incursión policial a la escuela Diaz, la mayoría de cuerpos de mujeres que vemos son cuerpos agredidos, llenos de sangre y encima de una camilla (Fotograma 10), mientras que todos los otros cuerpos (de periodistas, de los policías, de los políticos, de la gente que rodea a los y las que salen de la escuela) son varoniles. Durante toda la película vemos mujeres con las caras manchadas de sangre (Fotograma 11), otras pidiendo ayuda (Fotograma 12), otras en total estado de shock, otras abrazadas y protegidas por hombres (Fotograma 13), otras en camilla (Fotograma 14), algunas llorando (Fotograma 15): mujeres de todas las edades (Fotogramas 16 y 17).

Hay que tener presente que el mundo proyectado es algo fragmentario y fragmentado. Consideramos preocupante que en la película Bella Ciao se representen los cuerpos que se identifican o que identificamos con el género femenino mayoritariamente como cuerpos victimizados, maltratados y agredidos físicamente. Por el contrario, compartimos la reivindicación, la visibilización y la denuncia de las violencias sufridas por las personas manifestantes. Este de hecho se manifiesta como el primer discurso desarrollado por estas películas; la necesidad de generar una nueva memoria colectiva y
Fotograma 13

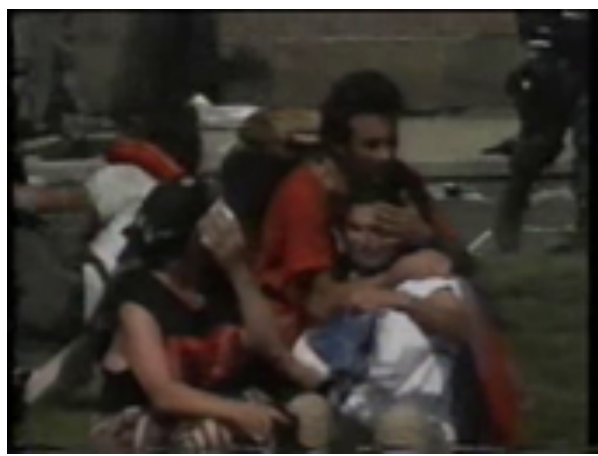

Fotograma 14

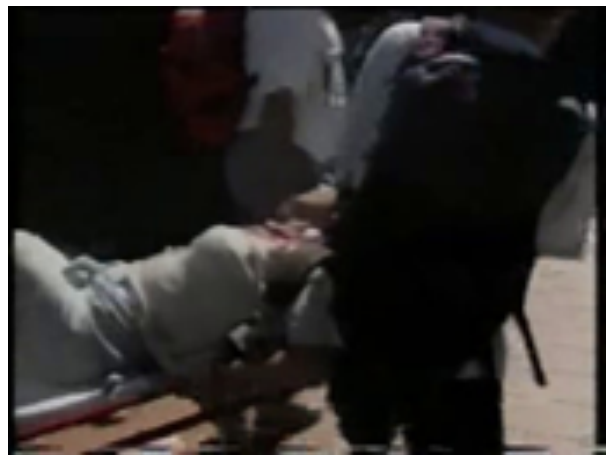

Fotograma 15

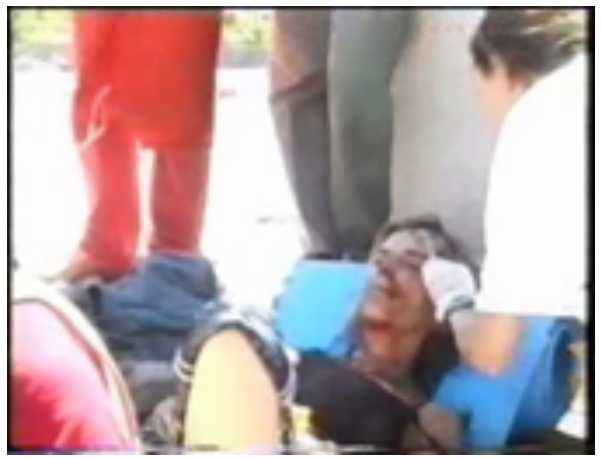


una nueva lectura de los acontecimientos se repite insistentemente a través del uso de vídeos amateur y de los testimonios. En el documental se manifiesta la denuncia de unas formas de acción política violentas y a la vez se intenta construir otra historia: conmemorar la memoria de Carlo Giuliani y reasignar a los y las manifestantes lo que con el poder institucional y de los medios de comunicación se les había quitado, el derecho a contar la violencia y los abusos de las fuerzas del orden y la resistencia de aquellos días. Así, el movimiento de la globalización desde abajo se repropia de la palabra, de la mirada y de la significación. Las imágenes amateurs de cuerpos agredidos, de gritos, de llantos, de sangre, de palizas, de miedos se convierten en prueba de lo vivenciado. En todo esto, Internet participa como dispositivo de creación de imágenes que a su vez generan y difunden la afirmación y reinterpretación de lo vivido. Es lo vivido lo que se hace testigo a través de la experiencia, del cuerpo. El público de este tipo de texto fílmico no solo recibe información, sino que participa de la creación de un texto y de una nueva memoria colectiva. Esta última se manifiesta a través de una implicación política que hace referencia a un nuevo y diferente vínculo con la interpretación fílmica de las realidades.

Concluyendo, podemos afirmar que la contra-cumbre del G8 de Génova de 2001 fue un campo de prueba para la realización de las denominadas 'políticas de/sobre la muerte'. El estado de excepción permanente y las tecnologías necropolíticas se realizaron a través del control de/sobre los cuerpos, a través de las amenazas, los abusos sexuales, el castigo, la tortura, la violencia psicológica y física, la vigilancia por tierra, mar y aire, la imposibilidad de algunos cuerpos (los de las personas manifestantes) de acceder a algunas zonas de la ciudad, la militarización de la misma, la detención injustificada en las cárceles o comisarias, etc. El estado de excepción, biopolítica y necropolítica representan las tres estructuras de poder fijas y cooperantes utilizadas por el Estado italiano durante el G8 de Génova. Desde nuestro punto de vista, cuando reflexionamos sobre el papel desarrollado por la violencia institucional y por la resistencia de los movimientos socia-
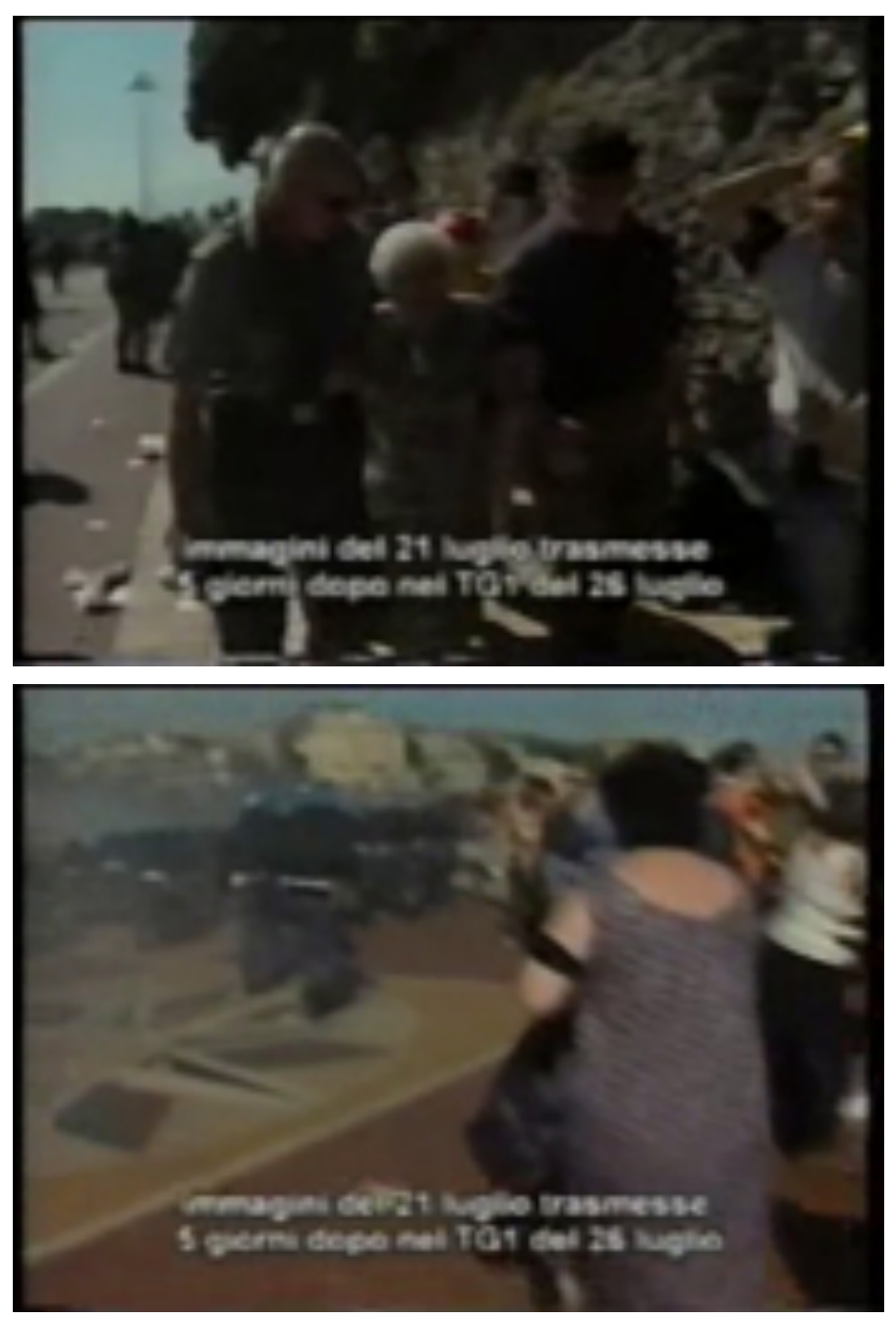

Fotograma 16 (arriba), fotograma 17 (abajo)

les durante el G8 de Génova, estamos investigando sobre las nuevas formas de las relaciones de poder que se están desarrollando en nuestro tiempo y que están definiendo la nueva tipología de sociedad en la que viviremos.

Las prácticas de control y la estrategia del miedo desarrolladas durante la contra-cumbre pueden ser interpretadas como dispositivos a través de los cuales el Estado italiano actuó durante el G8 de Génova, con el intento de generar la legitimidad ciudadana necesaria para poder usar la herramienta de la violencia militar, y para paralizar y castigar en su totalidad a un movimiento social transnacional. En dicha circunstancia, vemos los excesos del poder. 
Los testimonios de las personas que estuvieron en Génova en aquellos días narran las tecnologías de la violencia sobre las que teoriza Mbembe (2011): escupitajos, insultos, golpes, patadas, humillaciones, torturas, ejecuciones colectivas simuladas, interrogatorios, prisión, falta de servicios higiénicos y comida en las cárceles, abusos sexuales, constante vigilancia por tierra, mar y aire, gases lacrimógenos y homicidio. Todo esto describe una cierta toxicidad política del uso de la violencia, describe el exceso de la soberanía y su poder sobre la vida y la muerte. De esta forma, se define una nueva semiosis, una nueva relación de significación entre violencia y asesinato.

La necropolítica descrita por Mbembe define el derecho de matar como un concepto construido sobre la relación entre la idea ficticia de un enemigo, el estado de emergencia y el poder. Estos tres elementos, presentes durante la cumbre del G8 de Génova, constituyeron el terreno fértil para el desarrollo de las violencias militares. La condición de la aceptabilidad del homicidio - en términos de Mbembe-y la economía del biopoder y del necropoder, se hacen posibles en situaciones de extremo peligro y son elementos constituyentes del poder estatal.

El carácter híbrido del poder que se mueve entre el control biopolítico sobre la vida y el control necropolítico sobre la muerte se manifiesta principalmente a través de la gestión y la administración de los cuerpos. Es posible afirmar que durante los cuatro días de manifestación el control sobre los cuerpos se haya ejercido a través de diferentes formas: la forma más visible, era, sin duda, la represión física por parte de la policía, pero las formas de control sobre los cuerpos se manifestaron también de otros modos. Por ejemplo, la ausencia de fuentes en las calles, las actividades comerciales cerradas y la ausencia de servicios higiénicos públicos evidencian la idea de castigo sobre los cuerpos de las personas manifestantes. Así, negando las necesidades físicas primarias de las personas, se intentó atacar su presencia.

Tal como hemos considerado en el presente artículo, otra restricción impuesta a los cuerpos de las personas manifestantes fue la negación del acceso a la llamada Zona Roja. La militarización de la ciudad hizo visibles los límites impuestos a la presencia de los cuerpos. La inalcanzable e inexpugnable Zona Roja es una delimitación espacial inteligente, con el objetivo de identificar, por un lado, quién representa la soberanía, y por el otro, quién representa los movimientos sociales. El espacio político de la manifestación, la Zona Verde, es un lugar que se debe observar y controlar, es un espacio militarizado a través de la vigilancia.

Otra estrategia de la policía y de las fuerzas militares fue aquella del «miedo» ejercido a través del ruido de las porras contra los escudos, de las botas contra el suelo y de la persecución de las personas manifestantes. El cuerpo, en este caso, era el instrumento más grande de represión y de resistencia.

El estado de excepción permanente propuesto por Agamben se refleja en la biopolítica desarrollada durante la contra-cumbre. La aceptabilidad de estas políticas de la muerte se justifica y mantiene gracias al status necessitatis y a la legitimidad ciudadana generada por la estrategia del miedo y por la necesidad de seguridad. La condición del miedo guía los sujetos hacia la justificación y aceptación de la violencia, de la muerte y del asesinato como políticas de protección, transformando la ciudad democrática en una ciudad policíaca. Consideramos necesario subrayar el hecho de que necropolítica y biopolítica no son dos perspectivas antitéticas, sino que representan los nuevos dispositivos de gestión del poder de las sociedades disciplinarias analizadas por Foucault (1983). El concepto del autor sobre la presencia de una guerra social sin fin está presente en esta interpretación y explica la visión de la resistencia como acto intrínseco del poder.

Tal como hemos considerado en en este artículo, una de las formas de resistencia desarrolladas por el movimiento social de la globalización desde abajo fue la realización y distribución de películas documentales. Sobre los acontecimientos - asumimos este término siguiendo las categoías semióticas evidenciadas por Colaizzi (2006)del G8 de Génova, se han realizado, hasta hoy en día, 26 películas, todas militantes y todas accesibles desde el 
primer minuto y disponibles a través de Internet. Todas estas películas, denunciando las políticas violentas realizadas por el Estado y por las fuerzas del orden, parten de la necesidad de compartir informaciones diferentes respecto a las difundidas por los medios de comunicación institucionales, generar nuevos significados y crear otras memorias colectivas diferentes.

Sin embargo, en las películas, el análisis de la representación de las estructuras de poder entra en crisis si las analizamos desde una perspectiva feminista, evidenciando la interpretación fílmica de los eventos y de los sujetos teniendo en cuenta el género. Un elemento importante a subrayar es que en las películas falta por completo la representación de género no binario o trans, además se representa a las mujeres principalmente para visibilizar la violencia sobre los cuerpos. En las películas, las mujeres no parecen ser sujetos peligrosos, no son Black Blocks, sino que parecen más sujetos agredidos, victimizados. En los documentales no hay ninguna representación de todos aquellos movimientos feministas que participaron activamente en la contracumbre. La fragmentariedad de la representación de lo real se hace evidente aquí, invisibilizando el papel de las mujeres y de los movimientos feministas como subjetividades y colectividades resistentes.

Finalmente, en las películas analizadas, la representación de las tecnologías biopolíticas y la denuncia de las violencias llevadas a cabo por la policía son evidentes. Se presenta así la posibilidad de generar nuevos significados y nuevas memorias colectivas a través del uso de Internet como una herramienta que se manifiesta como agente activo para la creación y el desarrollo de las luchas transnacionales. Centrándonos en el análisis de las películas desde el punto de vista feminista, podemos considerar que la representación de las mujeres se manifiesta sobre todo a través de los cuerpos: cuerpos castigados, cuerpos maltratados, cuerpos abusados, pero también cuerpos resistentes, cuerpos que destacan a través de su presencia evidenciando el propio acto performativo de la revuelta.

Los textos fílmicos, por lo tanto, se insertan en aquella producción de artefactos que permite la resemiotización de la experiencia, de la memoria y de lo vivido. La película se convierte así en contenido, texto, cuerpo autónomo en movimiento y con una historia propia que contar, siempre en relación dialógica y dialéctica con el público.

\section{Bibliografía}

Agamben, G. Stato di eccezione. Torino: Bollati Boringheri editore, 2010.

Barthes, R. Lo obvio y lo obtuso. Barcelona: Paidós, 1986.

Barthes, R. La cámara lúcida. Nota sobre la fotografía. Barcelona: Paidós, 2009.

Bauman, Z. La globalización. Consecuencias humanas, Mexico D.F.: Fondo de cultura económica Mexico, 1999.

Bordwell, D. Narration in the Fiction Film. Madison: University of Wisconsin Press. 1985.

Braidotti, R. Il postumano. La vita oltre l'individuo, oltre la specie, oltre la morte. Roma: Derive Approdi, 2014.

Butler, J. (2007). El género en disputa: el feminismo y la subversión de la identidad. Barcelona: Paidós, 2007.

Carmona, R. Cómo se comenta un texto fílmico, Madrid: Cátedra, 1991.

Carrera, P., \& Talens, J. El relato documental. Madrid: Cátedra, 2018.

Casetti, F., \& Gromegna, A. G. El film y su espectador. Madrid: Cátedra, 1989.

Castells, M. La sociedad red: una vision global, Madrid: Alianza, 2006.

- Comunicación y Poder, Madrid: Alianza, 2009.

- Redes de indignación y esperanza, Madrid: Alianza, 2012.

Colaizzi, G. Feminismo y teoría fúlmica. Valencia: Episteme, 1995.

- (2001). «El acto cinematográfico: género y texto fílmico», Lectora, 7, 2001, pp. v-xiii

- Género y representación. Postestructuralismo y crisis de la modernidad, Madrid: Biblioteca Nueva, 2006.

- La pasión del significante. Teoría de género y cultura visual, Madrid: Biblioteca Nueva, 2007.

Codeluppi, V. La vetrinizzazione sociale. Torino: Bollati Boringhieri, 2007. 
Engels, F., \& Marx, K. Manifiesto comunista (Vol. 115). Madrid: Akal, 2004.

Foucault, M. No al sexo rey. Un diálogo sobre el poder. Madrid: Alianza, 1981.

Foucault, M. Vigilar y Castigar. Madrid: Siglo XXI, 1983.

Formenti, C. Cybersoviet. Utopie postdemocratiche e nuovi media, Milano: Raffaello Cortina Editore, 2008.

Mbembe, A. (2011). Necropolitica, Madrid: Melusina.

Mulvey, L. Placer visual y cine narrativo, Eutopias. Working Papers, Valencia: Episteme, 1988.
- Afterthoughts on Visual Pleasure and Narrative Cinema, in Feminist Film Theory, Su Thoruham, NY: New York University Press, 1989, pp. 31-40.

- Death $24 x$ a Second. Stillness and the Moving Image. Londres: Reaktion Books, 2009.

Nichols, B. La representación de la realidad: cuestiones y conceptos sobre el documental. Barcelona: Paidós, 1997.

Zumalde, I. \& Zunzunegui, S. Ver para creer. Avatares de la verdad cinematográfica, Madrid: Cátedra, 2019. 